\title{
Gel Formulation Containing Microcapsules of Grape Seed Oil (Vitis vinifera L.) for Skin Moisturizer
}

\author{
Silvia Surini*, Khansa Nursatyani, Delly Ramadon \\ Faculty of Pharmacy, University of Indonesia, Depok, Jawa Barat, 16424, INDONESIA.
}

\begin{abstract}
Objective: Grape seed oil (GSE) from Vitis vinifera L. has a high linoleic acid content, which plays a role in the skin moisturizing. However, linoleic acid is a liquid form and easily oxidized. The aims of this research were to prepare the microcapsules of GSE using ethylcellulose as coating polymer, and to formulate the gel containing the GSE microcapsules. Method: GSE microcapsules were prepared by solvent evaporation method with ethylcellulose in the ratio of $1: 1,1: 2,1: 3$ and $1: 4$ based on the amount of oil and polymer ratio. The produced GSE microcapsules were characterized such as the morphology, entrapment efficiency, particle size, and swelling index. The best microcapsules were formulated into a gel dosage form, and then evaluated. Results: The results showed that the microcapsules had a spherical shape and exhibited no pores, with the entrapment efficiency was in the range of 45.81 to $93.87 \%$. The mean volume diameters of F1, F2, F3, and F4 microcapsules were $83.58 \mathrm{~nm}, 129.40 \mathrm{~nm}, 151.15 \mathrm{~nm}$ and $202.74 \mathrm{~nm}$, respectively. The microcapsules showed the swelling index in the range of $49-73 \%$. Furthermore, the gel containing $2 \%$ GSE microcapsules
\end{abstract}

showed a good appearance and viscosity of $10,800 \mathrm{cps}$ with plastic flow property. Conclusion: The F4 microcapsules of GSE, which the ratio of GSE and ethylcellulose was 1:4, was the best microcapsules with the entrapment efficiency of $93.87 \%$. The GSE microcapsules that was incorporated into a gel formulation would be an interesting cosmetic product for skin moisturizer.

Key words: Ethylcellulose, Grape seed oil, Linoleic acid, Microencapsules, Solvent evaporation.

Correspondence

Silvia Surini, Faculty of Pharmacy, University of Indonesia, Depok, Jawa Barat, 16424, INDONESIA.

Phone: (021) 7270031

Email: silvia.surini@ui.ac.id

DOI: 10.5530/jyp.2018.10.11

\section{INTRODUCTION}

Grape (Vitis vinifera L.) seed oil (GSE) contains various chemical substances that can be used in various fields from food to cosmetics product. ${ }^{1}$ GSE contains double bond unsaturated fatty acid (Polyunsaturated fatty acids) as high as $85-90 \%$, which the major content is linoleic acid (omega 6), between $60-76 \%{ }^{2}$ GSE also contains other active compounds with a high antioxidant activity ${ }^{3}$ which can maintain the skin health, such as phytosterols, flavonoids, phenolic acids, carotenoids, tocopherols and tocotrienols which are the group of vitamin E isomers in the range of $1-53 \mathrm{mg} / 100 \mathrm{~g}$ oil. ${ }^{4}$

Although GSE has many benefits but, it has a weakness in terms of stability. The GSE stored at room temperature $\left(22^{\circ} \mathrm{C}\right)$ and exposed to light showed the damage that was characterized by an increase in the value of peroxide that reaches $484 \mathrm{meq} \mathrm{O}_{2} / \mathrm{kg}$ oil. ${ }^{5}$ The air and light exposure also accelerates the oxidation process of linoleic acid that affects and damages the stability of linoleic acid. ${ }^{6}$ The previous research data showed that it is important to formulate a dosage form that can protects and improves the stability of linoleic acid and grape seed oils such as microcapsules. ${ }^{7}$

Microcapsules is a modern dosage form which has been widely used to improve the stability of active substances or for any other medical purposes. ${ }^{8}$ Microcapsules is a single particle ranging from micrometers to millimeters sizes made of the solid or liquid material (core) and coated by a film of a polymeric material (shell). ${ }^{9}$ Some studies showed that microcapsules has been widely used for coating the active substances such as tocopherols, ${ }^{2}$ ascorbic acid and gallic acid, ${ }^{10}$ and folic acid. ${ }^{11}$ It can also be used for coating the core material in the form of essential oils such as rosemary oil, ${ }^{12}$ fish oil, and lavender oil. ${ }^{13}$ Based on those data, the microcapsules can be the right choice for protecting and maintaining the stability of GSE.

In this study, microencapsulation process was expected to increase the stability of GSE. The results will be dispersed into a gel dosage form to improve the effectiveness and comfort in the application of a moisturizer to the skin.

\section{MATERIALS AND METHODS}

\section{MATERIALS}

Grape seed oil (Jian Hairui Natural Plant, China), linoleic acid (Sigma Aldrich, Singapore), ethylcellulose (Aqualon, USA), methyl chloride (Merck, German), ethanol (Merck, German), methanol (Merck, Jerman), hexane (Merck, German), toluene (Merck, German), acetyl chloride (Sigma Aldrich, Singapore), Tween 80, Carbopol 940 (Lubrizol, Hongkong), Propylene glycol (Brataco, Indonesia), and triethanolamine (Brataco, Indonesia). Other solvents used were analytical grade.

\section{METHODS}

\section{Preparation of microencapsulated GSE by solvent evaporation method}

GSE microcapsules was prepared by the conventional solvent evaporation method at the room temperature $\left(25^{\circ} \mathrm{C}\right)$. GSE was dissolved in methyl chloride that strongly dissolves the oil derivatives. Ethanol was added gradually to the solution until well-homogenized. Ethylcellulose was added to the solution and mixed until homogeneous (referred as 
Solution A). In a separate container, water was used to dissolve Tween $80(0.1 \%)$ (referred as Solution B). Solution A was poured into the bottle and flowed through the pipe slowly (in droplets form) to the Solution $\mathrm{B}$ as the continuous phase. The drops speed was 9 drops $/ \mathrm{min}$. The mixture was stirred using a propeller tool at the speed of $2000 \mathrm{rpm}$ until the ethanol-methyl chloride were fully evaporated and the droplets formed. Microcapsules were filtered and then washed with water. Microcapsules immediately dried with a vacuum desiccator at room temperature. The scheme of microencapsulation process was shown at Figure 1. The process was repeated with the different amounts of grape seed oilethylcellulose ratio as shown at Table 1 .

\section{GSE microcapsules characterization Microcapsules recovery test}

Microcapsules recovery test was determined by comparing the weight of microcapsules obtained with the total mass of active ingredient and coating materials used in the following formulation.

$$
\begin{aligned}
\% \text { Microcapsules recovery test }= & \frac{\text { Microcapsule weight }}{\text { Microcapsule material }} \times 100 \% \\
& \text { forming weight }
\end{aligned}
$$

\section{Particle-size distribution}

The particle size distribution was measured using a particle size analyzer (Malvern Instruments, United Kingdom). The sample was dispersed in distilled water containing Tween $80(0.1 \%)$ as the continuous phase solution. Following the dispersion, its particle size distribution was measured.

\section{Microcapsules swelling index}

Microcapsules swelling index was determined by weighing $100 \mathrm{mg}$ of microcapsules, and the microcapsules were immersed into $10 \mathrm{~mL}$ of water as a medium in a conical tube, then it was left over for $120 \mathrm{~min}$. After that, centrifugation was performed for $10 \mathrm{~min}$ at $4000 \mathrm{rpm}$. The supernatant was removed and the final weight of the microcapsules was measured.

\section{Moisture content}

The moisture content of microcapsules was analyzed using a moisture analyzer (Mettler Toledo, Jerman). The samples (1000 mg) were placed on the aluminum disk and the moisture content was determined by heating the disk at $105^{\circ} \mathrm{C}$. The value listed on a moisture analyzer was recorded as the moisture content of the microcapsules.

\section{Microcapsules morphology and physical appearance}

The morphology and size of the microcapsules were evaluated by a scanning electron microscope (SEM) (FEI FE-SEM Inspect F50, USA). Samples were placed on the sample holder and coated with gold particles using fine coater. The samples were viewed and observed with 500x magnification.

\section{Entrapment efficiency of linoleic acid in the GSE microcapsules using gas} chromatography

The entrapment efficiency of microcapsules was determined by gas chromatography method with conditions as shown at Table 2 and Table 3.

\section{Lepage esterification method ${ }^{14}$}

Test solution $(2.0 \mathrm{ml})$ was pipetted, and then put into a test tube with a teflon lid and dried using flowing nitrogen gas. After completely dried, $400 \mu \mathrm{L}$ toluene and $1600 \mu \mathrm{L}$ of methanol were added while stirred using a vortex. Then, $200 \mu \mathrm{L}$ acetyl chloride was added slowly while stirred using magnetic stirrer. The tube was sealed and heated in an oven $\left(100{ }^{\circ} \mathrm{C}\right)$ for $60 \mathrm{~min}$. Furthermore, the tube was cooled in the water, and then $5.0 \mathrm{~mL}$ potassium carbonate (6\%) was slowly added into the tube while stirred using vortex. Then, the tube was sealed and centrifuged at $3000 \mathrm{rpm}$ for $10 \mathrm{~min}$.

\section{Preparation of linoleic acid standard solution}

Linoleic acid standard was carefully weighed at $500 \mathrm{mg}$ then put in a 20.0 $\mathrm{mL}$ volumetric flask. Linoleic acid standard was dissolved in hexane, and readjusted the volume until the lines on the flask to obtain the concentration at $25.0 \mathrm{mg} / \mathrm{mL}(25,000 \mathrm{ppm})$. Then, the standard solution was diluted to obtain some certain concentrations. Each concentration was undergone esterification process using Lepage method, described previously. One microlitre of toluene layer (upper layer) containing methyl linoleic was separated, then injected into the gas chromatography.

\section{Preparation of the sample solution of the GSE microcapsules}

Each sample of the GSE microcapsules carefully weighed equivalent to $9.50 \mathrm{mg}$ of linoleic acid and then inserted into a volumetric flask. Samples were dissolved in hexane using sonicator. Then, the sample solution was esterified by Lepage method. The resulting supernatant $(1.0 \mu \mathrm{L})$ containing methyl linoleic was utilized for gas chromatography analysis. The drug entrapment efficiency was determined using the following formula:

$\%$ Drug entrapment efficiency $=\frac{\text { Experimental linoleic acid content }}{\text { Theoritical linoleic acid content }} \times 100 \%$

\section{Preparation of gel dosage form containing the grape seed oil microcapsules}

The gel was prepared by dispersing carbomer in the water while stirred until completely dispersed. Triethanolamine was added into the carbomer gel base using homogenizer at stirring speed $1500 \mathrm{rpm}$. Propylene glycol was mixed into the gel base by stirring in the homogenizer at the speed of $1500 \mathrm{rpm}$ until the entire gel base well-homogenized. Furthermore, GSE microcapsules which has been dispersed in the $10 \mathrm{~mL}$ of distilled water were added into the gel base. The mixture was homogenized using a homogenizer at stirring speed of $1500 \mathrm{rpm}$ until the microcapsules were fully dispersed in the gel base. The gel formulation of the GSE microcapsules is showed in Table 4.

\section{Evaluation of the gel containing GSE microcapsules}

\section{Physical appearance of the GSE microcapsules gel}

Gel appearance was evaluated through the existence of discoloration, odor changes, and gel phase separation.

\section{Determination of spreadability}

The spreadability of the gel formulation was determined by applying gel on the glass object and then observed under the microscope. The gel formulation must show a homogeneous composition.

\section{Determination of $\mathrm{pH}$}

$\mathrm{pH}$ of the gel was determined by a digital $\mathrm{pH}$ meter (Eutech Instrument, Singapore). Firstly, the electrode was calibrated with standard buffer $\mathrm{pH}$ 4 and $\mathrm{pH}$ 7. Gel sample ( $1 \mathrm{~g}$ ) was dissolved in $10 \mathrm{ml}$ of distilled water and the electrode was then dipped into the solution until constant reading obtained. The constant reading of $\mathrm{pH}$ value was recorded. The measurements of $\mathrm{pH}$ were replicated three times.

\section{Viscosity and flow properties measurement}

Viscosity measurement was determined by Brookfield viscometer (Brookfield, USA). The gel was put into a container of beaker glass and mounted using spindle 5. Measurement was carried out with varying 
speeds, from $0.5 ; 2 ; 5 ; 10$; and $20 \mathrm{rpm}$, then back to the opposite of $20 ; 10$; $5 ; 2$ and $0.5 \mathrm{rpm}$. The viscosity was indicated by the red needle note, then multiplied by a correction factor according to the instrument manual. The flow property can be obtained by plotting the curve between shearing stress (F/A) against the rate of shear (dv/dr).

\section{RESULTS}

\section{Preparation of the microencapsulated GSE by the solvent evaporation method}

In this research, GSE microencapsulation by solvent evaporation method was chosen because it was considered as the easiest method than others. ${ }^{15}$ Additionally, this method produces microcapsules with a high entrapment efficiency, a good coating and a low residual of organic solvents. ${ }^{16}$

\section{Characterization grape seed oil microcapsules Microcapsules recovery test}

Microcapsules recovery test value illustrates the efficiency of the microcapsules preparation process. The higher of the value, the more efficient the process of microcapsules preparation process and the use of the material with the result no wasted material of microencapsulation process. The microcapsules recovery test value was shown in Table 5 with the ranged from $40 \%$ to $78 \%$, the highest value was F4 in 78\% and the lowest was $\mathrm{F} 1$ in $40 \%$.

\section{Microcapsules morphology and physical appearance}

The morphology and physical appearance of microcapsules were investigated by scanning electron microscope Figure 2. The fourth formula microcapsule has exhibited no pores.

\section{The entrapment efficiency of microcapsules}

The entrapment efficiency was determined the number of drugs which was entrapped in the microcapsules, ethylcellulose. The value of entrapment efficiency can describe the efficiency of the methods. Table 5 shows the entrapment efficiency of microcapsules from various formulations. The value of entrapment efficiency was in the range of 45.81 to $93.87 \%$. The lowest entrapment efficiency was F1 microcapsules with $45.81 \%$, while the highest was F4 microcapsules with $93.87 \%$.

\section{Particle size distribution}

Determination of particle size distribution used was $\mathrm{dv}$ value or particle size distribution based on the sample volume because there was heterogeneity of particle size in the fourth formulation as shown at Figure 3. The particle size distribution by volume was more representative because it was directly related to the volume of the particle measured. Table 6 shows the values of dv10, dv50, dv90, and dvmean for each microcapsules.

\begin{tabular}{ccccc}
\hline \multirow{2}{*}{ Table 1: Microcapsules formulation of grape seed oil (Vitis vinifera $\mathbf{L}$.) } \\
\hline Materials & \multicolumn{5}{c}{ Formulation } \\
\cline { 2 - 5 } & $\mathbf{1}$ & $\mathbf{2}$ & $\mathbf{3}$ & $\mathbf{4}$ \\
\hline Grape seed oil (gr) & 1.0 & 1.0 & 1.0 & 1.0 \\
Ethylcellulose (gr) & 1.0 & 2.0 & 3.0 & 4.0 \\
Ethanol (mL) & 10 & 20 & 30 & 40 \\
Dichlorometane (mL) & 10 & 20 & 30 & 40 \\
Tween 80 (ml) & 0.1 & 0.2 & 0.3 & 0.4 \\
Water (ml) & 100 & 200 & 300 & 400 \\
Drug-polymer ratio & $1: 1$ & $1: 2$ & $1: 3$ & $1: 4$ \\
\hline
\end{tabular}

\section{Moisture content}

Moisture content represents the capability of the matrix in protecting the drugs inside from humidity. Based on the test results, the value of moisture content of all formulations was between 2.46 to $3.18 \%$ (Table 5).

\section{Microcapsules swelling index}

Figure 4 shows the swelling index of microcapsules in the distilled water as medium samples with the habitation in $\min 60$ and 120. The value of swelling index ranged between $49-73 \%$. There was not any differences in the index values of all microcapsule formulations between min 60 and 120 . The selected microcapsules for gel formulation was the formula with a spherical shape, the highest entrapment efficiency, and the largest particle size distribution. Formulation with the largest particle size distribution was chosen because microcapsules can be seen properly and dispersed well in the gel base. Based on the entrapment efficiency data, the microcapsules formula selected was F4 because it had a spherical particle shape, the highest entrapment efficiency $(75.10 \%)$ and particle size distribution $\mathrm{D}_{\text {mean }}$ volume $202.74 \mu \mathrm{m}$.

\section{Gel evaluation}

\section{Physical appearance of the GSE microcapsules gel}

GSE microcapsules gel was seen white transparent powder as microcapsules spread well over the gel formulation. Figure 5 shows the results of the GSE microcapsules gel.

\section{Determination of spreadability test}

GSE microcapsules gel showed a homogenous gel when viewed using a glass object under the microscope.

\section{Determination of $\mathrm{pH}$}

The $\mathrm{pH}$ of the gel was between 5.55-5.58. The results of $\mathrm{pH}$ measurement were reflected the $\mathrm{pH}$ balance of the skin, which was between 4.5-6.5. So that, the gel will not irritate the skin and improve comfort in use.

\section{Viscosity and flow properties test}

The determination of viscosity and flow properties of the gel was used spindle 5 at a speed of $5 \mathrm{rpm}$. The value of viscosity was showed 10,800 cps and rheogram of flow property is shown at Figure 6.

\section{DISCUSSION}

In this study, ethylcellulose was chosen as a coating agent because it is a water-insoluble hydrophobic polymer. ${ }^{17}$ Ethylcellulose has been used as

\begin{tabular}{cc} 
Table 2: Chromatography gas analysis condition \\
\hline Parameter & Condition \\
\hline Column & Cyanopropil methyl sil (capilary column) \\
Column dimension & $\mathrm{p}=60 \mathrm{~m}, \varnothing$ inside $=0.25 \mathrm{~mm}, 0.25 \mathrm{~m}$ film \\
thickness \\
$\mathrm{N}_{2}$ flow rate & $30 \mathrm{~mL} / \mathrm{min}$ \\
$\mathrm{He}_{\text {flow rate }}$ & $30 \mathrm{~mL} / \mathrm{min}$ \\
$\mathrm{H}_{2}$ flow rate & $40 \mathrm{~mL} / \mathrm{min}$ \\
Air flow rate & $400 \mathrm{~mL} / \mathrm{min}$ \\
Split ratio & $1: 80$ \\
Injection volume & $1 \mu \mathrm{L}$ \\
Linier velocity & $23.6 \mathrm{~cm} / \mathrm{sec}$ \\
Injector temperature & $220^{\circ} \mathrm{C}$ \\
Detector temperature & $240^{\circ} \mathrm{C}$ \\
Column temperature & Temperature program \\
\hline
\end{tabular}




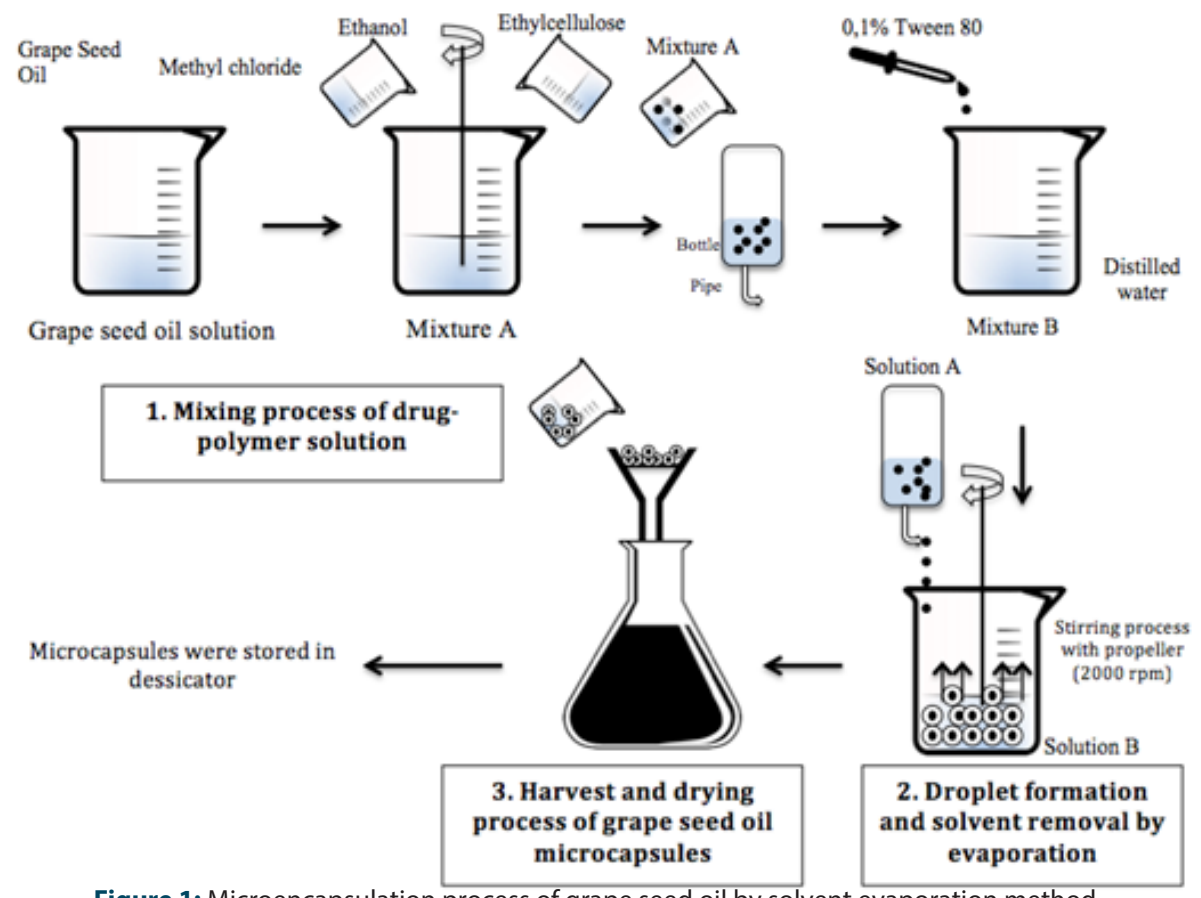

Figure 1: Microencapsulation process of grape seed oil by solvent evaporation method.
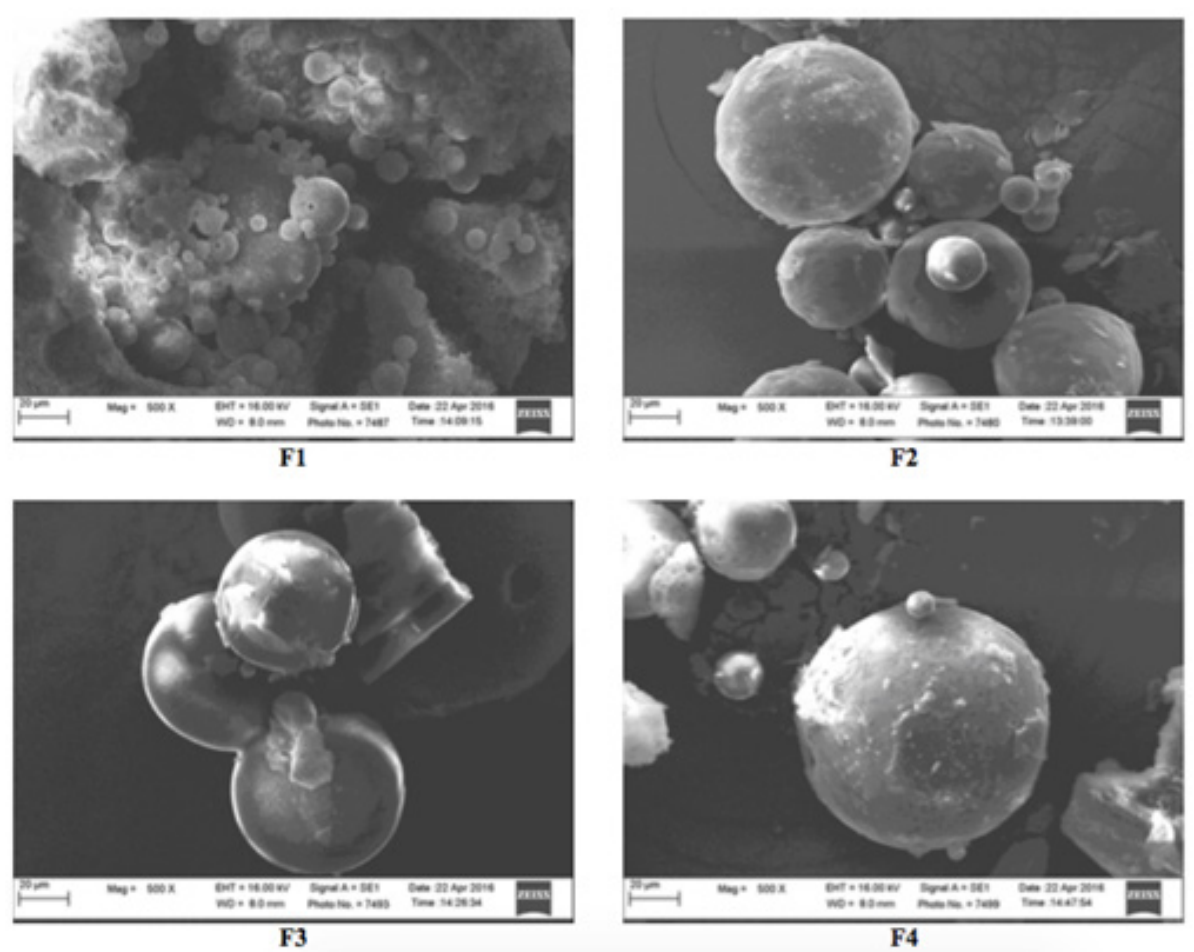

Figure 2: Scanning electron microphotographs of the grape seed oil microcapsules of F1, F2, F3, and F4 with 500x magnification.

the polymer forming of the microparticles to cover the unpleasant taste and smell as well as for increasing the stability of easily oxidized active components. Solvent evaporation method was used to prepare the GSE microcapsules because it can mix two types of solvents, such as methyl chloride for dissolving the GSE (as an active ingredient) and ethanol for dissolving the ethylcellulose (as a coating agent). These two types of solvents, methyl chloride-ethanol, is called as an azeotrope mixture. It helps the evaporation process of the solvent from the coating solution and forms the microcapsules that was not aggregate each other. ${ }^{18}$ Furthermore, Tween 80 , a non-ionic and water soluble surfactant, decreased the interfacial tension and formed a continuous film between the microcapsules particles, so tat the aggregation of the particles can be avoided. Among the other formulas, F1 showed the smallest value of entrapment efficiency because $\mathrm{F} 1$ was produced in a a few amount microcapsules than the other. It was caused by a small concentration of the polymer used, so that the active ingredient can not be fully entrapped. Inequality 
between the polymer and the drug concentration caused the unsuccessful coating of GSE in the ethylcellulose before the solvent evaporated. Consequently, the uncoated oil was left in a bottle and the pipe drops. After the GSE was coated in the polymer, the drugs inside the microcapsules were well protected by the factors that can disrupt its stability, such as humidity, water, light, and others.

The results showed that the microcapsules had a spherical shape and various sizes. Mixing speed is one of the factors that affect the shape and size of the microcapsules. The size and spherical shape of microcapsules were depended on the speed of stirring in the medium or continue phase solution. ${ }^{8}$ By reducing the speed, the size of the microcapsules would increase. Furthermore, the drying conditions of the microcapsules also

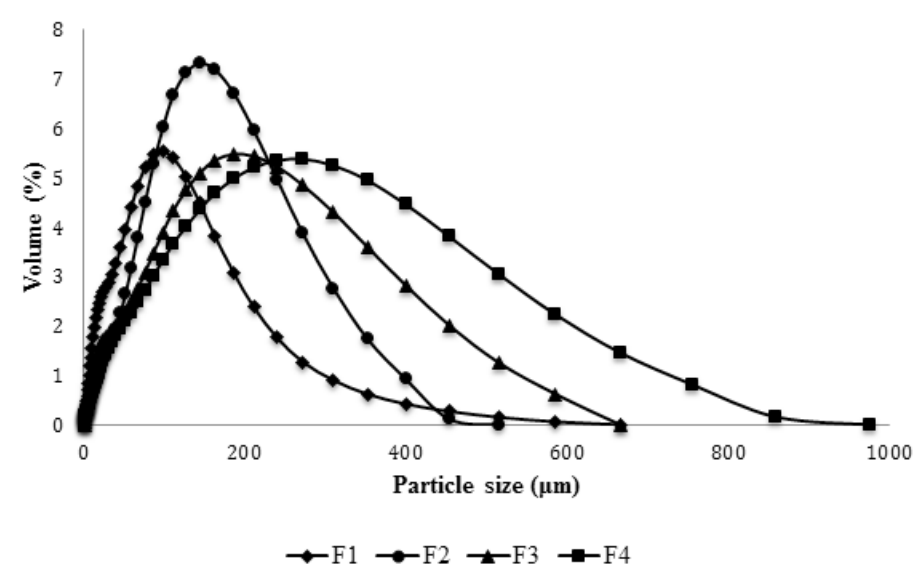

Figure 3: Particle size distribution of the grape seed oil microcapsules.
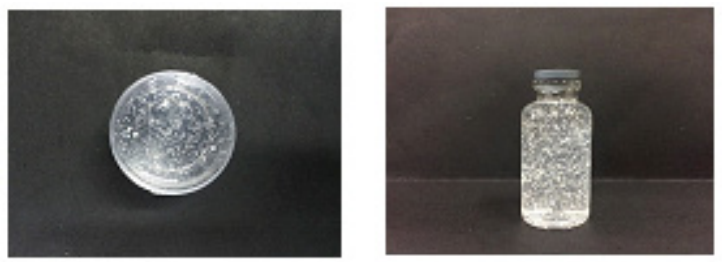

Figure 5: Physical appearance of the grape seed oil microcapsules gel.

\begin{tabular}{|c|c|c|}
\hline Rate $\left({ }^{\circ} \mathrm{C} / \mathrm{min}\right)$ & Temperature $\left({ }^{\circ} \mathrm{C}\right)$ Hold & Time (min) \\
\hline - & 125 & 5 \\
\hline 10 & 185 & 5 \\
\hline 5 & 205 & 10 \\
\hline 3 & 225 & 7 \\
\hline
\end{tabular}

Table 4: Gel formulation of grape seed oil microcapsules

\begin{tabular}{cc}
\hline Materials & Concentration $(\% \mathrm{~b} / \mathrm{b})$ \\
\hline Carbopol 940 & 0.50 \\
Triethanolamine & 1.00 \\
Propylene glycol & 15.00 \\
Grape seed oil microcapsules & 2.00 \\
Water & $\mathrm{ad} 100$ \\
\hline
\end{tabular}

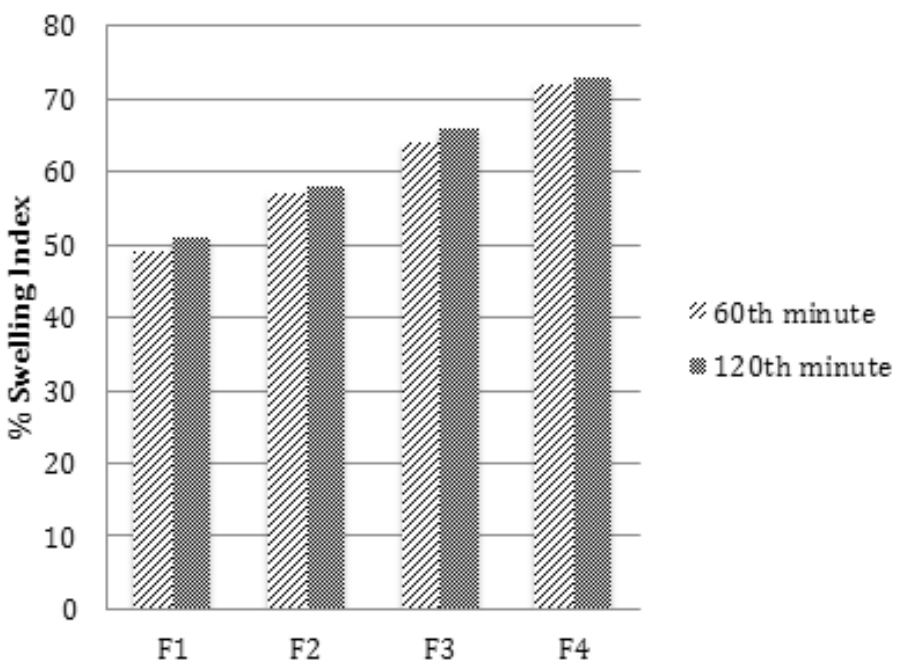

Figure 4: Swelling index of the grape seed oil microcapsules in distilled water as medium.

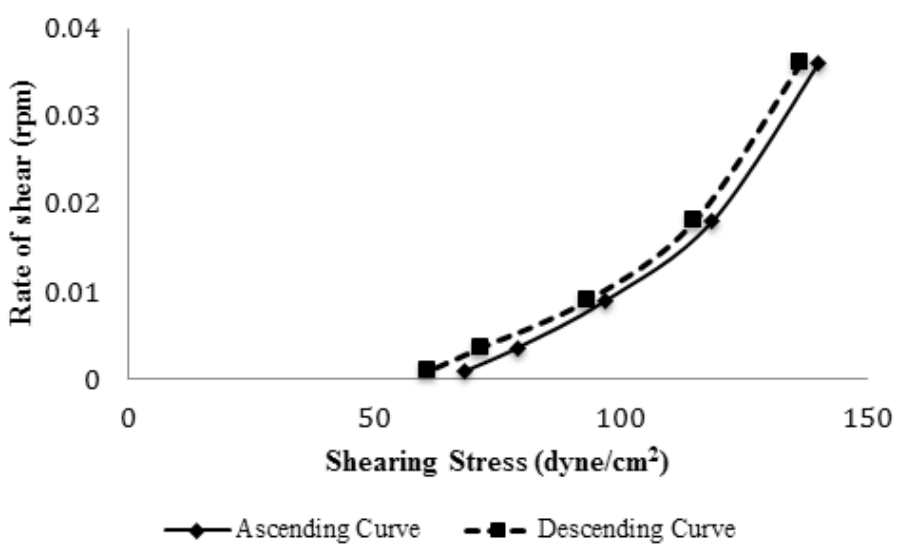

Figure 6: Rheogram of flow property of the grape seed oil microcapsules gel.

\begin{tabular}{|c|c|c|c|}
\hline Formulation & $\begin{array}{l}\text { Recovery test } \\
\text { (\%) }\end{array}$ & $\begin{array}{l}\text { Entrapment } \\
\text { efficiency (\%) }\end{array}$ & $\begin{array}{c}\text { Moisture } \\
\text { content (\%) }\end{array}$ \\
\hline 1 & 40.0 & 45.81 & $3.18 \pm 0.03$ \\
\hline 2 & 53.3 & 58.63 & $3.10 \pm 0.05$ \\
\hline 3 & 67.5 & 58.61 & $3.10 \pm 0.10$ \\
\hline 4 & 78.0 & 93.87 & $2.46 \pm 0.09$ \\
\hline
\end{tabular}

\begin{tabular}{ccccc}
\multicolumn{5}{c}{ Table 6: Particle measurements of the grape seed oil microcapsules } \\
\hline Formulation & $\begin{array}{c}\mathbf{d v 1 0} \\
(\mu \mathrm{m})\end{array}$ & $\begin{array}{c}\mathbf{d v 5 0} \\
(\boldsymbol{\mu m})\end{array}$ & $\begin{array}{c}\mathbf{d v 9 0} \\
(\mu \mathrm{m})\end{array}$ & $\begin{array}{c}\mathbf{D}_{\text {mean }} \text { volume } \\
(\boldsymbol{\mu m})\end{array}$ \\
\hline 1 & 11.7 & 68.1 & 193 & 83.58 \\
2 & 26.3 & 124 & 268 & 129.40 \\
3 & 14.9 & 129 & 356 & 151.15 \\
4 & 22.8 & 172 & 478 & 202.74 \\
\hline
\end{tabular}


can be resulted from the less spherical form of microcapsules and variable sizes. The drying process of the microcapsules can be done in various ways including the drying at room temperature conditions $\left(27^{\circ} \mathrm{C}\right)$, and using a vacuum to reduce the pressure or with the heat energy. ${ }^{16}$ The variety of drying conditions would be resulting from the different of morphology and porosity of the microcapsules.

The microphotograph F1 with a ratio 1:1 between GSE and ethylcellulose shows that the amount of ethylcellulose which is equivalent to the amount of GSE was not able to cover the entirely GSE. F1 has a nonspherical form with the small part that was separated each other. This results were different from F2, F3 and F4 which had a higher ethylcellulose concentration. They showed the spherical without small parts that were split each other. It was caused by the increase of ethylcellulose concentration in F2, F3, and F4, so that ethylcellulose could coat the overall amount of oil concentration.

Microcapsules formula with a higher polymer concentration had a high value of entrapment efficiency compared to formula with a smaller polymer concentration. The results revealed that F1 with smallest polymer concentration had the lowest value of entrapment efficiency compared to other formulas. F1 has the lowest concentration of ethylcellulose than the F3 and F4, so that ethylcellulose coud not cover the entire amount of oil contained in microcapsules formulation. On the other hand, F4, a formula which the polymer concentration four times more than the amount of oil, showed the highest value of entrapment efficiency.

The entrapment efficiency will increase by the rise of the polymer concentration used. ${ }^{19}$ Increasing the viscosity of the polymer-drug solution and solidification time can be applied to reduce the porosity of the microparticles. Thus, it can prevent the drug to diffuse out of the continuous phase. The influence of the polymer concentration on the efficiency of the encapsulation process can be explained in two ways. First, at a very high concentration, the polymer will settle more quickly on the surface of the dispersed phase and prevent the diffusion of the drug crosses the line between the dispersed phase with the continuous phase. Sec, the high concentration of polymer will increase the viscosity of the solution and prevent the diffusion of the drug in a droplet of polymer solution. ${ }^{20}$ Another important characteristicis particle size distribution. Figure 3 displays the particle size distribution curves of the microcapsules formulas. The results of the measurement of particle size distribution of all formulas shows the sequence from the smallest particle size was F1 < F $<$ F $3<$ F4. It can be seen in Table 6 that the higher of polymer concentration, the wider particle size distribution curve, and the particle size will increase. The increasing of ethyl cellulose concentration would significantly influences the increasing of average microcapsules diameter. ${ }^{11}$ This may be caused by an increase of the medium viscosity from high polymer concentrations that affected the increase of interfacial tension. Furthermore, the solvent evaporation method was produced the variation of the particle size distribution which is not only influenced by the differences in the concentration of the polymer but also influenced by the speed of stirring. The particle size of microcapsules can be controlled by increasing the stirring speed at medium solution. ${ }^{21}$ The stirring speed was the main parameter in controlling the size of droplets of a mixture of the drug and polymer solution..$^{21}$ By increasing the stirring speed in the continuous phase would generally result in decreasing the size of the microcapsules because it would produce the smaller droplets through a strong shear force and the increased turbulence.

Based on the water content measurement result, water that was entrapped in the microcapsules can be derived from the use of distilled water in the preparation of the microcapsules. Ethylcellulose has characteristics that are stable and not affected by the water. Ethylcellulose has been permeated by the water from the air or during immersion in the water with a very small amount which can be evaporated. This suggested that the microcapsules were not hygroscopic because ethylcellulose wasnot affected by the water, so the use of ethylcellulose as a polymer coating would be more stable if it is put in a gel formulation. It showed that the ethylcellulose has a hydrophobic and nonporous property which was not able to absorb the water in large quantities.

The swelling index curve of all formulas showed that the particle size and the amount of polymer concentration affect the swelling properties of the microcapsules. Microcapsules F4 with the higher polymer concentration was seen more swell than the F1, F2, and F3 with the smaller polymer concentration. In addition to these factors, the particle size also affects the value of the swelling index of the microcapsules, as in F1 and F2 which had the smaller size than the other formulas. The smaller of the particle size, the less of medium permeated which was inversely proportional to the increase the polymer concentration, cause the bigger the value of swelling index.

After the microcapsules was obtained, it was formulated into a gel dosage form. GSE microcapsules gel was made using carbomer as a gel base. The use of carbomer as a gel base produced a $\mathrm{pH}$ that is acidic so it needs the addition of triethanolamine (TEA), which is alkaline to neutralize the $\mathrm{pH}$ of the gel formulation and get the $\mathrm{pH}$ balance of the skin to increase the coziness of using gel formulation. ${ }^{22}$ The concentration of GSE microcapsules that was formulated into the gel dosage form is as much as $2 \%$. This concentration was equivalent to the concentration range of GSE used in the topical preparations for moisturizing the skin is between $2-5 \%$.

Based on the rheogram in Figure 6, it was seen that the flow properties of the gel were plastic thixotropy. The rheogram shows plastic flow because the curve was not pass through the 0,0 ordinate, but cut the axis of the shearing stress at a certain point, known as the yield value. The materials that exhibit the plastic flow known as Bingham bodies. Bingham bodies would not flow until the shearing stress-related to the yield value was exceeded. Thixotropic can be seen from the location of the descending curve of the gel was on the left of the ascending curve and both curves almost coincide. Plastic thixotropic flow properties have a meaning that with the addition of shear stress, the viscosity of dosage decreases or becomes more dilute. ${ }^{23}$

\section{CONCLUSION}

The grape seed oil microcapsules prepared by solvent evaporation using ethylcellulose as a coating polymer in the ratio of 1:4 (the F4 formula) is the best microcapsules with the entrapment efficiency of $93.87 \%$. The gel containing the grape seed oil microcapsules has been successfully produced and it could be an interesting cosmetic product for skin moisturizer.

\section{ACKNOWLEDGMENT}

The authors gratefully acknowledge to Directorate of Research and Community Engagements of Universitas Indonesia for financial support.

\section{CONFLICT OF INTEREST}

The authors have no conflict of interest to declare.

\section{ABBREVIATION USED}

GSE: Grape seed oil; SEM: Scanning electron microscope; TEA: Triethanolamine.

\section{REFERENCES}

1. Korac RR, Khambholja KM. Potential of herbs in skin protection from ultraviolet radiation. Phcog Rev. 2011;5:164-73.

2. Otadi M, Zabihi F. Vitamin E microcapsulation by ethylcellulose through emulsion 
solvent evaporation technique; An operational condition study. World Appl Sci J. 2011;14:20-5.

3. Devi S, Singh R. Antioxidant and Anti-Hypercholestrolemic Potential of Vitis vinifera Leaves. Pharmacogn J. 2017;9(4):565-72.

4. Shinagawa FB, Santana FC, De RL, Torres O, Mancini-filho J. Grape seed oil : A potential functional food. Food Sci Technol. 2015;35(3):399-406.

5. Lachman J, Hejtmánková A, Kotíková Z, Dddina M, Stralková R, Hönig V. Stability of grape seed oil and its antioxidant tocotrienols. Adv Mat Res. 2014;10301032:370-3

6. Belcadi-haloui R, Zekhnini A, Hadek ME, Hatimi A. Effect of light and oxygen on argan oil stability during a long-term storage. Int J Innov Res Sci Eng Technol. 2015;4(2):8-14

7. Devi VK, Jain N, Valli KS. Importance of novel drug delivery system in herbal medicines. Phcog Rev. 2010;4(7):27-31.

8. Thakur L, Ghodasra U, patel N, Dabhi M. Novel approaches for stability improvement in natural medicines. Phcog Rev. 2011;5(9):48-54.

9. Mali SD, Khochage SR, Nitalikar MM, Magdum CS. Microencapsulation: A review. Int J Pharma Bio Sci. 2012;3(1):509-31.

10. Tandale SR. Microencapsulation of vitamin $c$ and gallic acid in whey protein concetrate by spray and freeze drying - characterization and degradation kinetics. [master's thesis]. [Georgia (US)]: University of Georgia; 2007.

11. Prasetmanakit S, Praphairaksit N, Chiangthong W, Muangsin N. Ethyl cellulose microcapsule for protecting and controlled release of folic acid. AAPS PharmSciTech. 2009;10(4):1104-12.

12. Voncina B, Kreft $\mathrm{O}$, Kokol V, Chen WT. Encapsulation of rosemary oil in ethylcellulose microcapsules. Text Res J. 2009;1(1):13-9.

13. Jin-Mei W, Wei Z, Qin-Weng S, Hong Z, Ying Z. Preparation and characterization of natural fragrant microcapsules. JFBI. 2009;1(4):293-300.
14. Lepage G, Roy CC. Direct transesterification of all classes of lipids in a-one-step reaction. J. Lipid Res. 1986;27:114-20

15. Li M, Rouaud O, Poncelet D. Microencapsulation by solvent evaporation: State of the art for process engineering approaches. Int J Pharm. 2008;363(1-2):26-39.

16. Freitas S, Merkle HP, Gander B. Microencapsulation by solvent extraction/ evaporation: Reviewing the state of the art of microsphere preparation process technology. J Control Release. 2004;102(2):313-32.

17. Murtaza G. Ethylcellulose Microparticles: A Review. Acta Pol Pharm. 2012; 69(1):11-22.

18. Jelvehgari M, Montazam SH. Comparison of microencapsulation by emulsionsolvent extraction/evaporation technique using derivatives cellulose and acrylatemethacrylate copolymers as carriers. Jundishapur J Nat Pharm Prod. 2012; 7(4):144-52.

19. Ramadon D, Wirarti GA, Anwar E. Novel Transdermal Ethosomal Gel Containing Green Tea (Cammelia sinensis L. Kuntze) Leaves Extract: Formulation and In vitro Penetration Study. J Young Pharm. 2017;9(3):336-40.

20. Witschi C, Doelker E. Influence of the microencapsulation method and peptide loading on poly(lactic acid) and poly(lactic-co-glycolic acid) degradation during in vitro testing. J Control Release. 1998;51(2-3):327-41.

21. Yu D, Qiao W, Li Q, Pei G. Preparation and properties of olive oil microcapsules experiment materials preparation of microcapsules. JFBI. 2012;5(1):67-76.

22. Anwar E, Ramadon D, Harmita. Formulation and Evaluation of Gel and Emulge of Chili Extract (Capsicum frutescens L.) as Topical Dosage Forms. Int J Pharm Pharm Sci. 2014;6(3):13-6.

23. Anwar E, Utami TD, Ramadon D. Transfersomal Gel Containing Green Tea (Camellia sinensis L. Kuntze) Extract: Increasing in vitro Penetration. Asian J Pharm Clin Res. 2017;10(8):294-8.

Article History: Submission Date : 27-07-2017; Revised Date : 31-08-2017; Acceptance Date : 04-11-2017.

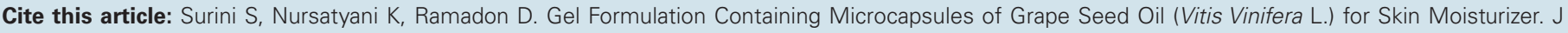
Young Pharm. 2018;10(1):41-7. 